\title{
Mergers and acquisitions stochastic cooperative games
}

\author{
Pavel V. Konyukhovskiy, Maria A. Nastych \\ Saint Petersburg State University, Saint Petersburg, Russia
}

\section{Email address:}

aura2002@yandex.ru(P. V. Konyukhovskiy), nastych@bk.ru(M. A. Nastych)

\section{To cite this article:}

Pavel V. Konyukhovskiy, Maria A. Nastych. Mergers and Acquisitions Stochastic Cooperative Games, International Journal of Economic Behavior and Organization. Vol. 1, No. 2, 2013, pp. 20-26. doi: 10.11648/j.jjebo.20130102.11

\begin{abstract}
Study of the formation and subsequent behavior of the companies' coalitions are becoming increasingly important in today's economy. In the elementary case, the process of collaboration may be represented as a classical cooperative game with transferable utility. However, the assumption of the possibility of describing the potential winnings of coalitions using deterministic values seems very controversial. Hypothesis of their random nature is much more realistic. The paper presents the conversion from classical cooperative game theory with side-payments to stochastic analog. Game theory modeling of mergers and acquisitions processes is based on this class of games here.
\end{abstract}

Keywords: Cooperative Game Theory, Stochastics, VaR, Mergers and Acquisitions, Quantile

\section{Introduction}

Cooperative behavior of economic agents is becoming particularly relevant in the context of globalization and information exchange streamlining. Amalgamate entities pursue the goals of strengthening their market position and influence whether it's a mutual cooperation or hostile takeover. Coalitions formation between the firms can lead both to the establishment of monopoly power through consolidation, and to products and services quality improvement and/or price decreasing by, for example, implementation of partner design and innovation. The result depends on the degree of concentration in the market where interacting firms operate.

Companies can cooperate with each other in the two possible forms: in the form of strategic cooperation without formal capital relocation or in the form of creating a new company with the rights and obligations of two or more considering economic agents while some of them if not all stop to exist, i.e. mergers and acquisitions (M\&A). Each of these forms of coalition behavior can be vertical or horizontal integration or conglomerate. Choice of the form and type of cooperative behavior depends on strategic goals, institutional characteristics and other factors.

The essential feature here is that the appellations "merger" and "acquisition" conform to the Russian law terms. Thus, merger is an integration of two or more economic entities which produces a new unified economic unit while in the case of acquisition all target companies lose their independence and cease to exist and acquire gets all the rights and obligations of the liquidated companies.

The current practice of analyzing the effectiveness of the strategic cooperation between the two companies does not involve the use of conventional instruments of analysis, due to the contractual basis of the behavior of the coalition. Meanwhile, due to coalition behavior affects the companies' fair price value such a methodology becomes necessary, especially when the strategic alliance includes more than two companies. Analysis of effectiveness of mergers and acquisitions between companies under the corporate finance theory is dedicated to the same issue. It should be mentioned that such verification is to consider only two coordinating companies.

This work proposes a solution to this problem through the use of cooperative game theory, which will expand both the range of application and the conclusions of analysis of economic integration on the corporate finance theory's results basis. Here as well we reject the prerequisite for the possibility of representing the gains $v(S)$ of each coalition $S \subset I$ in the form of deterministic values. More plausible and therefore more attractive is the assumption that these gains are random variables $\tilde{v}(S)$ with some known distribution functions as in [1] or [2]:

$$
F_{\tilde{v}(S)}(x)=\mathrm{P}\{\tilde{v}(S) \leq x\} .
$$

Thus, we consider the formation of strategic alliances and mergers and acquisitions as a stochastic cooperative game with transferable utility. Let us call this class of models as MSCG (Mergers and Acquisitions Stochastic Cooperative Games). 


\section{Game-Theory Modelling of Economic Integration}

\subsection{Stochastic Cooperative Games}

We define further the stochastic cooperative games (SCG). $\operatorname{SCG}(I, \tilde{v})$ is defined by a finite set of players $I=\{1, \ldots, n\}$ and the stochastic characteristic function $\tilde{v}: 2^{I} \rightarrow \mho$, which is a random variables defined on the set of all subsets of $I$ with known densities $p_{\tilde{v}(S)}(x)$ and $\tilde{v}(0)=0$. The elements of subset $S \subset I$ are called coalitions. Distribution densities $p_{\tilde{v}(S)}(x)$ are interpreted as gains (benefits, payoffs) of appropriate coalitions $S \subset I$.

Let us consider in more detail the issues related to approaches to the benefits definition in stochastic cooperative games.

A solution concept in nonstochastic cooperative game $(I, v)$ is usually considered (in [3], [4], for example) as an allocation $x \in \mathbb{R}^{n}$, where $n=|I|$, satisfying the following conditions:

(a) individual rationality

$$
\forall i \in I \quad x(i) \geq v(i)
$$

(b) group rationality

$$
\sum_{i=1}^{n} x(i)=v(I)
$$

One possible way to obtain analogues of conditions (1)-(2) for stochastic cooperative games is the requirement for their fulfillment for some level of probability $\alpha$. Thus, the allocation of the SCG can be defined as a vector $x(\alpha) \in \mathbb{R}^{n}$, that satisfies

(a) stochastic analog for individual rationality

$$
\forall i \in I \quad \mathrm{P}\left\{x_{\alpha}(i) \geq \tilde{v}(i)\right\} \geq \alpha
$$

(b) stochastic analog for group rationality

$$
\mathrm{P}\left\{\sum_{i=1}^{n} x_{\alpha}(i) \leq \tilde{v}(I)\right\} \geq \alpha
$$

Note that the stochastic analog for individual rationality (3) essentially means that the proportion of the player $i$ according to $x_{\alpha}$ must exceed the value of the random variable of his individual gain with probability no less than $\alpha$. In this condition, the component $i$ of the vector $x_{\alpha}$ is compared with the $\alpha$-quantile of $F_{\tilde{v}(i)}(x)$ - the distribution function of the random variable $\tilde{v}(i)$. For compactness, we introduce further designations:

$$
\tilde{v}_{\alpha}(i)=F_{\tilde{v}(i)}^{-1}(\alpha)
$$

for player $i$ and

$$
\tilde{v}_{\alpha}(S)=F_{\tilde{v}(S)}^{-1}(\alpha)
$$

for coalition $S \subset I$. Then condition (3) can be represented as

$$
\forall i \in I \quad x_{\alpha}(i) \geq \tilde{v}_{\alpha}(i)
$$

The transition from inequality (3) to inequality (7) is justified, based on the property of non-decreasing of the distribution function. Indeed, a condition $x_{\alpha}(i) \geq \tilde{v}(i)$ that is true at some level of probability $\alpha$ will be satisfied for all $\alpha^{\prime}>\alpha$.

In classical cooperative games group rationality condition (2) implies the need for full distribution of the grand coalition utility within the allocation. In the proposed modification to the stochastic game, it can be interpreted as the sufficiency of the grand coalition's payoff to realize the imputations $x_{\alpha}$.

Taking into account the introduced notations, stochastic game allocation is determined by the conditions

$$
\begin{aligned}
& \text { (a) } \quad \forall i \in I \quad x_{\alpha}(i) \geq \tilde{v}_{\alpha}(i) \\
& \text { (b) } \sum_{i=1}^{n} x_{\alpha}(i) \leq \tilde{v}_{\alpha}(I) \forall i \in I \quad x_{\alpha}(i) \geq \tilde{v}_{\alpha}(i)
\end{aligned}
$$

The term value at risk (VaR) is steadily entrenched for the variables $\tilde{v}_{\alpha}(I)$ in the modern risk management, for example, see [7]. Thus, among the advantages of the approach (8)-(9) to the allocation definition in stochastic cooperative games there is the fact that it connects the values of the allocation components with the VaR values of the random game parameters. This advantage potentially gives ample opportunities for meaningful interpretation of results in further research of this class of games' properties and concepts to determination of the allocation.

\section{2. $M \& A$ Stochastic Cooperative Games}

For MSCG we assume here that random variables $\tilde{v}(S)$ is normally distributed with parameters $v(S)$ and $\sigma_{S}^{2}$, i.e.:

$$
\tilde{v}(S) \sim N\left(v(S), \sigma_{S}^{2}\right) .
$$

This assumption objectively consistent with some economic characteristics of the simulated values, allowed implementation of which we can describe as symmetric intervals $\pm 3 \sigma_{i}$ arranged with respect to some of the expected average $v(i)$.

Efficiency justification process of mergers and acquisitions in the corporate finance theory is reduced to establishing positive synergistic effect that occurs as a result of the growth of capitalization. Capitalization growth is the main companies' objective in accordance with the modern economic theory as in Koller et al. [8]. Synergy is an effect of two or more companies' interaction resulting in exceeding their aggregate fair price value above the cumulative amount of their initial values.

As firms seek to maximize their capitalization, characteristic function is defined as the expectation of the coalitions' cost of business. Denote fair value of the coalition $S$ by $V_{S}$ and the cost of its formation by $P_{S}$. Then we have:

$$
v(S)=V_{S}-P_{S}
$$

Recall that if for any two disjoint coalitions $S$ and $T$ the inequality $v(T)+v(S) \leq v(T \cup S)$ is true, then in classical cooperative games we conclude that function $v(S)$ is su- 
peradditive. Stochastic analog for the superadditivity related to the probability $\alpha$ can be specified as

$$
\forall S, T: S \cap T=\emptyset \quad \mathrm{P}\{\tilde{v}(T)+\tilde{v}(S) \leq \tilde{v}(T \cup S)\} \geq \alpha
$$

Let $\boldsymbol{S}_{S}$ be a synergistic effect for the coalition S. Then,

$$
\boldsymbol{S}_{S}=V_{S}-\sum_{i \in S} V_{i}-P_{S}
$$

Obviously the synergy is nonnegative if and only if the characteristic function determines the superadditive game. Thus, in terms of cooperative game theory the economic integration is suitable in the case of characteristic function superadditivity.

In order to simplify the model we assume here that the coalition formation cost is the amount of external services for each of the companies involved in the coalition:

$$
P_{S}=\sum_{i \in S} P_{i}
$$

This assumption may be explained by the fact that the coalition formation is quite a lengthy process and does not require the simultaneous accession of all participants. Due to this assumption this parameter is insignificant to determine the feasibility and sustainability of the overall coalition. Point is that a characteristic function, which is the sum of two superadditive ones, is also superadditive in the classical cooperative game theory. According to the SCG it is not necessarily true, but according to MSCG it is true as an expectation of a constant value. Therefore we can simplify the characteristic function as:

$$
v(S)=V_{S}
$$

There are cost-based, comparative and income approaches to value a company. In the current international practice the first method is not commonly used due to objective reasons. Thus, according to the cost method the company fair value equals to the value of its assets without the debt. But the net book value of a business has no bearing on the case however great it could be [4]. For example, the book value depends on the moment of each asset inclusion in balance sheet and on the depreciation method chosen by the company.

Comparative evaluation method is based on the market multiples calculation for the certain company and the industry as a whole. Due to these market multiples analysts draw conclusions about company's undervaluation or overvaluation and its potential. The weakness of this methodology using for MSCG modeling is the fact that there is a significant specific set of multipliers for each separate industry. Secondly, most of the multipliers can be calculated only for companies whose shares are freely traded. Thirdly, some companies' multiples just must be above or below the industry average due to specific features of these companies.

Thereby, in this article we consider the determination of the business fair value based on the income approach, or discounted cash flow method (DCF):

$$
\mathrm{v}(\mathrm{S})=\sum_{\mathrm{t}=1}^{\infty}\left(\mathrm{FCF}_{\mathrm{t}}^{\mathrm{S}}\right) /\left(1+\mathrm{WACC}^{\mathrm{S}}\right)^{\mathrm{t}},
$$

$$
v(S)=\sum_{t=1}^{\infty} \frac{F C F_{t}^{S}}{\left(1+W A C C^{S}\right)^{t}},
$$

where $F C F_{t}^{S}$ is free cash flow (FCF) of coalition $S$ in the year $t$ and $W A C C_{t}^{S}=W A C C^{S}$ is weighted average cost of capital for the coalition $S$. According to Gordon's model characteristic function can be defined as:

$$
\begin{gathered}
\mathrm{v}(\mathrm{S})=\sum_{\mathrm{t}=1}^{\mathrm{T}}\left(\mathrm{FCF}_{\mathrm{t}}^{\mathrm{S}}\right) /\left(1+\mathrm{WACC}^{\mathrm{S}}\right)^{\mathrm{t}}+ \\
+\left(\mathrm{FCF}_{\mathrm{T}+1}^{\mathrm{S}}\right) /\left(\mathrm{WACC}^{\mathrm{S}}-\mathrm{g}^{\mathrm{S}}\right)\left(1+\mathrm{WACC}^{\mathrm{S}}\right)^{\mathrm{T}+1}, \\
v(S)=\sum_{t=1}^{T} \frac{F C F_{t}^{S}}{\left(1+W A C C^{S}\right)^{t}}+\frac{F C F_{T+1}^{S}}{\left(W A C C^{S}-g^{S}\right)\left(1+W A C C^{S}\right)^{T+1}},(17)
\end{gathered}
$$

where $T$ is length of FCF forecasting period and $g^{S}$ is terminal FCF growth rate of the coalition $S$ and $\forall S g^{S}<$ WACC ${ }^{S}$.

Let then $R_{t}^{S}$ be operating revenue, $E x_{t}^{S}$ be operating expenses, $T_{t}^{S}$ be absolute value of the deducted tax, CAPEX $X_{t}^{S}$ be the amount of capital expenditures and $N I_{t}^{S}$ be net investments in the year $t$ :

$$
F C F_{t}^{S}=R_{t}^{S}-E x_{t}^{S}-T_{t}^{S}-C A P E X_{t}^{S}+N I_{t}^{S}
$$

These indicators should be calculated for each coalition according to the form (strategic alliances, mergers and acquisitions) and the type (horizontal integration, vertical integration and conglomerate) of the companies' cooperative behavior.

The weighted average cost of capital rate in this model is calculated on the basis of the policy of available resources distribution ratio within the coalition and of the tax rate. Tax rate may vary in dependence, for instance, on whether in the coalition the company with the tax benefits right exists or on the country of common coalition residence. WACC is calculated also based on the ratio $\beta^{S}$ :

$$
\begin{aligned}
& \text { WACC }^{\mathrm{S}}= \mathrm{k}_{\mathrm{d}}^{\mathrm{S}}\left(1-\operatorname{tax}^{\mathrm{S}}\right) \mathrm{D}^{\mathrm{S}} /\left(\mathrm{D}^{\mathrm{S}}+\mathrm{E}^{\mathrm{S}}\right)+ \\
&+\mathrm{k}_{\mathrm{e}}^{\mathrm{S}} \mathrm{E}^{\mathrm{S}} /\left(\mathrm{D}^{\mathrm{S}}+\mathrm{E}^{\mathrm{S}}\right) \\
& \text { WACC }^{S}= \frac{D^{S}}{D^{S}+E^{S}} k_{d}^{S}\left(1-\operatorname{tax}^{S}\right)+\frac{E^{S}}{D^{S}+E^{S}} k_{e}^{S} \\
& k_{e}^{S}=r_{f}+\beta^{S}\left(r_{m}-r_{f}\right)
\end{aligned}
$$

Here, $D^{S}$ is amount of coalition $S$ debt, $E^{S}$ is its equity, $\operatorname{tax}^{S}$ is corporate income tax rate, $k_{d}^{S}$ is rate of return on debt, $k_{e}^{S}$ is rate of return on equity, $r_{m}$ is market rate of return and $r_{f}$ risk-free rate of return.

The modern literature on the theory of corporate finance, for instance in [6], accepted to correct the coefficient $\beta^{S}$ for certain coalition as an average coalition's beta weighted by cost of equity in accordance with the international global market as a result of the capital market globalization.

$$
\begin{gathered}
\beta^{\mathrm{S}}=\sum_{\mathrm{i} \in \mathrm{S}}\left(\beta^{\mathrm{i}} \mathrm{E}^{\mathrm{i}}\right) / \sum_{\mathrm{i} \in \mathrm{S}} \mathrm{E}^{\mathrm{i}} \\
\beta^{S}=\frac{\sum_{i \in S} \beta^{i} E^{i}}{\sum_{i \in S} E^{i}}
\end{gathered}
$$


In special cases there is the possibility to optimize some of these indicators. In such situations relative formulas will differ in dependence of form and type of cooperative behavior. For example, in the way of different countries' residents merger a new venture may have an opportunity to choose a country for residence. Obviously, in this case, his choice will be largely justified by the system of corporate taxation in these countries. Considering an acquisition an indicator of corporate income tax rate will match the relative tax rate of acquirer's country of residence.

There is a difference in the pattern of changes in operating and financial performance between the strategic alliance form of coalition behavior and behavior by the type of M\&A. In the second case it varies by actual changes in balance sheet and all departments and parties association. In the first case we can observe the lack thereof.

Cooperation within the framework of diversification and vertical integration does not allow optimizing the structure of production costs while horizontal integration does. Structure optimization of such external costs as the cost of marketing and $R \& D$ or the cost of debt service are available for all three types considered. The ability to optimize the structure of fixed costs also exists for all of types of integration. The set of these cost items may include, for example, joint use of warehouse and industrial premises. In the case of vertical integration, it may also include the costs optimization of which is related to the specifics of companies' chain activities constructing. It contains the various stages of processing and maintenance of manufactured product, usually carried out on the basis of several enterprises. Diversification allows reducing the fixed costs associated with providing related products to consumers. Horizontal integration is characterized by the decrease of fixed costs associated with work with suppliers. For M\&A cooperation it is possible to achieve costs reduction by optimizing the structure of the new company being formed. Namely it is possible to eliminate the departments' duplication functions, to reduce the number of employees with similar functions.

Using these cost estimates for coalitions it is possible to calculate their total operating costs with the help of forecasted future volumes of goods and services they provide. In itself, the business integration that occurs as a result of companies' coalition behavior is likely to lead to growth of demand on providing goods and services due to, for example, increase of trust, brand awareness, sales outlets, due to sharing client databases. Diversification and vertical integration facilitate to decline the risk by reducing the volatility of the companies' revenue stream and improve companies' stability to external economic conditions.

Worth noting, however, that the assumption of the company's commitment to maximize the value of the business is not always satisfied in general as well as the assumption of rationality of players. If we assume the possibility of irrational behavior or non-economic purposes of cooperating companies, the M\&A game model can be extended to the case of the characteristic function with side-payments. Cooperative companies can, for example, pursue the goals of their parent companies, the state, the private individuals. Thus, the benefits derived by the players can be different.

If the assumption of a striving for maximize capitalization is satisfied, the value of the characteristic function reflects the total fair value for each coalition. Then the game solution, that is, the gains allocation among the players, is the fair value of each player separately. Cooperative game theory expects each coalition's players to have their own goals. In other words, each company-participant makes a decision on cooperation on the basis of possible change in its own gain to increase capitalization. Nonetheless, interpretation of the game solution also depends on the cooperation form.

In the case of strategic alliance companies remain formally independent economic agents. Thereby the characteristic function is hypothetical while gains allocation does not. The decision to cooperate certainly affects the value of business, changing cash flow and making it impossible to calculate their fair value separately from coalition's partners. Fair value calculation in accordance with standard methodology ignores this fact. So, the definition of gains allocation through the characteristic function value becomes necessary when planning as important financial company's indicators.

In contrast in the case of M\&A deals the characteristic function is not hypothetical and allocation vector do often so. Nevertheless, terminating participants' activity as a separate business, coalitions often hold their brands under new one company. Further, mergers and acquisitions can be implemented in the form of equity stakes purchase or equity stakes exchange. Hypothetical property of gains allocation is useful for possible coalition splitting.

Another important interpretation of the allocation vector is a fair acquisition price or fair value of exchangeable shares for the merger. It is usually the most controversial issues in conducting such deals. Thus, the assessment of companies that have or will undergone conversion by merger or acquisition is a key issue of financial and strategic planning.

\section{MSCG Model Application}

Increasing role of these possible forms of coalition behavior can be observed, for example, in the aviation industry which is strategically important for Russia. In particular, the international market of passenger air transportation has significant potential for our country due to the geographical position of Russia, business activity growth, increasing role of the international business, social and political relations.

In order to achieve greater efficiency in the international market competitive Russian airlines are seeking to increase the number of routes, quality of service, reduce costs, integrating into alliances and concluding interline agreements and agreements on code-sharing with foreign players. Saturation of the world airlines market leads to the need of consolidation through mergers and acquisitions. Air alliances and airlines groups are gaining importance and scope 
in the airline business.

The closure of Russian market by virtue of state share participation and control prevents the active participation of foreign companies in performing domestic scheduled flights on the one hand, and thus cause lethargy in negotiations with Russian airlines. The state of domestic fleet is another factor that prevents involvement of Russian airlines in the international market. Russia's accession to the WTO is leading to significant changes in the field. Thus, the possible consolidation of Russian and foreign companies analysis, withdrawal of administrative barriers, such as a limit on foreign pilots working in domestic companies, established by the Air Code, begins to play a key role in an effort to achieve economic efficiency of the international aviation industry.

As an example, consider the incident occurred in 2008. According to information provided by the Thomson Reuters, it has been rumored that British Airways PLC, Royal Jordanian, the Turkish Turk Hava Yollari AO, the French AIR France-KLM, the German Deutsche Lufthansa AG, the Chinese Air China Ltd and the Russian Aviakompaniya Sibir' OAO are the potential bidders for the $42.75 \%$ stake in the Austrian Airlines AG. On 25 August 2008, Deutsche Lufthansa AG has officially declared interest in buying part of Austrian Airlines. On 27 August 2008, Aviakompaniya Sibir' OAO has officially declared interest in buying part of Austrian Airlines AG. On 28 August 2008, Turkish Turk Hava Yollari AO has officially declared interest in buying part of Austrian Airlines AG. On 11 September 2008 Turkish Turk Hava Yollari AO has announced that it cannot take part in the bidding for Austrian Airlines AG because its notification of intentions reached relevant authority after the stated deadline. On 11 September 2008, AIR France-KLM officially declared interest in buying part of Austrian Airlines AG. On 15 September 2008, British Airways PLC officially declared no interest in buying part of Austrian Airlines AG. On 16 September 2008 Air China Ltd has announced that it hasn't made an offer for share capital of Austrian Airlines AG. On 15 October 2008 it was announced that Aviakompaniya Sibir' OAO has refused the purchase of Austrian Airlines.

For simplicity, we will model the three entities game with Turk Hava Yollari, Sibir' and Austrian Airlines despite the fact that subsequently company was acquired by Lufthansa AG. This choice can be explained by the fact that only the Turkish and Russian companies officially declared that they made an offer to the Austrian company to buy its shares.

Table 1. Tables may span across both columns

\begin{tabular}{|c|c|c|c|c|c|c|c|}
\hline \multirow{2}{*}{ Coalitions } & & & \multicolumn{5}{|c|}{ Free cash flows } \\
\hline & & & 2012 & 2013 & 2014 & 2015 & 2016 \\
\hline- & & & 0,00 & 0,00 & 0,00 & 0,00 & 0,00 \\
\hline Turk Hava Yollari & & & 2155,9 & 3200,9 & 5001,9 & 7029,1 & 9394,3 \\
\hline Sibir' & & & 6740,8 & 10261,4 & 15094,9 & 21687,7 & 30953,4 \\
\hline Austrian Airlines & & & 412,1 & 49,1 & 298,7 & 355,2 & 420,5 \\
\hline Turk Hava Yollari & Sibir' & & 8898,0 & 13639,5 & 20103,1 & 28727,0 & 40363,2 \\
\hline Turk Hava Yollari & Austrian Airlines & & 2568,1 & 3594,9 & 5300,7 & 7384,6 & 9815,1 \\
\hline Sibir' & Austrian Airlines & & 7153,0 & 10549,6 & 15393,6 & 22043,0 & 31374,0 \\
\hline Turk Hava Yollari & Sibir' & Austrian Airlines & 9310,2 & 13893,8 & 20401,9 & 29082,4 & 40784,1 \\
\hline
\end{tabular}

Table 2. WACC calculation

\begin{tabular}{|c|c|c|c|c|c|c|}
\hline & & & Cost of debt, $\$$ mln & Debt, \$ mln & Equity, \$ mln & WACC \\
\hline- & & & 0,00 & 0,00 & 0,00 & - \\
\hline Turk Hava Yollari & & & 419,9 & 2782,7 & 2119,0 & $12,2 \%$ \\
\hline Sibir' & & & 1672,0 & 10320,2 & 153,7 & $12,9 \%$ \\
\hline Austrian Airlines & & & 375,0 & 606,1 & 10864,9 & $8,6 \%$ \\
\hline Turk Hava Yollari & Sibir' & & 1977,0 & 13102,9 & 2272,7 & $12,2 \%$ \\
\hline Turk Hava Yollari & Austrian Airlines & & 511,3 & 3388,8 & 12983,9 & $8,1 \%$ \\
\hline Sibir' & Austrian Airlines & & 1770,2 & 10926,3 & 11018,6 & $9,9 \%$ \\
\hline Turk Hava Yollari & Sibir' & Austrian Airlines & 2068,4 & 13709,0 & 13137,6 & $10,0 \%$ \\
\hline
\end{tabular}


Table 3. Stochastic game model for Tturk Hava Yollari, Sibir' and Austrian airlines

\begin{tabular}{|c|c|c|c|c|c|}
\hline & \multirow{2}{*}{ Coalitions } & & \multirow{2}{*}{ Growth rate } & \multicolumn{2}{|c|}{ Gains, USD bln } \\
\hline & & & & $v(S)$ & $\sigma$ \\
\hline - & & & 0,00 & 0,00 & 0,00 \\
\hline Turk Hava Yollari & & & $1,19 \%$ & 103,35 & 0,97 \\
\hline Sibir' & & & $1,26 \%$ & 321,67 & 0,12 \\
\hline Austrian Airlines & & & $0,84 \%$ & 6,61 & 0,13 \\
\hline Turk Hava Yollari & Sibir' & & $1,26 \%$ & 443,41 & 1,09 \\
\hline Turk Hava Yollari & Austrian Airlines & & $1,19 \%$ & 162,99 & 1,10 \\
\hline Sibir' & Austrian Airlines & & $1,26 \%$ & 425,17 & 0,24 \\
\hline Turk Hava Yollari & Sibir' & Austrian Airlines & $1,26 \%$ & 544,78 & 1,22 \\
\hline
\end{tabular}

According to data provided by the Thomson Reuters, we calculated the weighted average cost of capital rate, forecasted the cash flow for the period 2012-2016 and growth rate in the post-forecast period for all possible coalitions.

In order to forecast future cash flows invariability of current corporate income tax rate was assumed $(20 \%$ for Turkey $^{1}$ and Russia ${ }^{2}$, and $25 \%$ for Austria ${ }^{3}$ ). Considered counties signed treaties for the avoidance of double taxation between each other.

Let us assume a coalition form of strategic alliance for Turkish and Russian companies and acquisition for other possible coalitions with Austrian company included. Cash flow projections for each possible coalition (Table 1) is based on the above considerations about the nature of the transformation of each of the operating and financial components.

To determine the cash flow discount rate (Table 2) using the above formulas we calculated firstly the values of $\beta^{i}$ for each airline $i, r_{m}$ and $r_{f}$. The risk-free rate of return was estimated by the 15 years average monthly yield of thirty-years U.S. Treasury bonds, following [9]. It is equal to $3.96 \%$. Value of the market risk premium was calculated by the median of the differences of monthly yields of S\&P500 and the monthly yields of thirty-years Treasury bonds over 15 years. It is equal to $6.84 \%$. The value $\beta^{i}$ for each country was derived as the ratio of the covariance of monthly yields of the local index and S\&P500 to the value of VaR, following [10]. We used the following indexes: Istanbul SE Ulusal 100 Index for Turkey, RTS for Russia, Austrian Traded Index for Austria.

Terminal growth rate of cash flows (Table 3) for every coalition $S$ is given by the formula: $g^{S}=i n f l^{S}+a^{S}$, where infl $l^{S}$ is inflation and $a^{S}$ is CF free nominal growth.

In accordance with the DCF valuation method the gains for all possible coalitions were calculated (Table 3).

The variance $\sigma_{S}$ was calculated using the data on considered companies capitalization for the last 10 years.

Based on the superadditivity, expediency of Turkish and Russian companies' integration into a strategic alliance for

\footnotetext{
${ }^{1}$ Low N 5520, 21.07.2006, Turkey

${ }^{2}$ Federal law N 368-FL, 27.12.2009, Russian Federation

${ }^{3}$ Law on corporate taxation, 1998, Austria
}

the joint purchase of Austrian Airlines can be concluded. Buying an Austrian company is appropriate as well in the case of its acquisition for both companies individually.

It is interesting that a fair contribution according to Shapley value of Austrian Airlines (Table 4) to the total coalition's gain 10 times greater than its initial fair value. Given received synergies thanks to the cooperation, the value of $\$ 63.18$ billion can be regarded as a fair price to be paid for $100 \%$ of Austrian Airlines shares.

Table 4. Shapley value

\begin{tabular}{lll}
\hline Turk Hava Yollari & Sibir & Austrian Airlines \\
\hline 120,67 & 360,93 & 63,18 \\
\hline
\end{tabular}

\section{Conclusion}

The article explains the conversion from classical cooperative game theory basic terms to stochastic analogs. By dint of SCG methodology the models of companies' integration were discussed. Considered in the last part example of the acquisition in the airline industry clearly showed the potential application and conclusions obtained with the proposed methodology using. Further transition of classical cooperative games' instruments to the SCG reveals other features of this class such as the Core restriction.

\section{Nomenclature}

\section{References}

[1] Suijs, Jeroen, and Peter Borm. "Stochastic cooperative games: superadditivity, convexity, and certainty equivalents." Games and Economic Behavior 27.2 (1999): 331-345.

[2] Конюховский, П. В., "Применение стохастических кооперативных игр при обосновании инвестиционных проектов,” Вестник СПбГУ. 2012, Сер, 5(4), pp.134-143.

[3] Gibbons, Robert, "Game theory for applied economists," Princeton University Press, 1992

[4] Печерский, С. Л., and А. А. Беляева, “Теория игр для экономистов.” СПб: Изд-во Европейского университета в С.-Петербурге, 2001. 
[5] Jorion, Philippe, "Value at risk: the new benchmark for managing financial risk," Vol. 2. New York: McGraw-Hill, 2007.

[6] Koller, Tim, Marc Goedhart, and David Wessels. "Valuation: measuring and managing the value of companies." Vol. 499. Wiley, 2010.

[7] Валдайцев, С.В., “Оценка бизнеса и управления стоимостью предприятия”, Экономика, 1, 2. М.: Проспект,
2012.

[8] Moulin, H., "Fair division and collective welfare." London, England.: The MIT Press. Cambridge, Massachusetts, 2004.

[9] Damodaran, A., “Applied Corporate Finance” ( $3 \mathrm{~d}$ ed.). Wiley, 2010 .

[10] Brealey, Richard A., Stewart C. Myers, and Franklin Allen, "Corporate finance," Vol. 8. McGraw-Hill/Irwin, 2006. 